\title{
Safety and Efficacy of Oral Melatonin When Combined with Thoracic Epidural Analgesia in Patients with Bilateral Multiple Fracture Ribs
}

\author{
Ahmed M Fetouh \\ Abdelrahman' \\ Amany Faheem Abdel Salam \\ Omara' \\ Alaa Ali M Elzohry (D) $^{2}$ \\ 'Anesthesia and Surgical ICU, Faculty of \\ Medicine, Tanta University, Tanta, Egypt; \\ ${ }^{2}$ Department of Anesthesia, ICU and Pain \\ Relief, South Egypt Cancer Institute, \\ Assiut University, Assiut, Egypt
}

This article was published in the following Dove Press journal: Local and Regional Anesthesia

Background: The purpose of this study is to evaluate the safety and efficacy of oral melatonin administered with thoracic epidural analgesia in patients with multiple bilateral fractured ribs.

Patients and Methods: A prospective, double-blind randomized control study was carried out on 80 patients of either sex, American Society of Anesthesiologists (ASA) Grade I and II, aged above 18 years, presenting with multiple bilateral fractured ribs. They were randomly divided into two groups, 40 patients each. Placebo group patients received oral placebo tablets and melatonin group (TEA and melatonin) patients received oral melatonin tablets $(5 \mathrm{mg}$ ), about 1 hour before epidural infusion of local anesthetics and then every 12 hours till the cessation of bupivacaine infusion.

Results: Melatonin administration was associated with a significant decrease in total morphine analgesia consumption, from $31.8 \pm 1.41 \mathrm{mg}$ in the TE group to $13.03 \pm 0.85 \mathrm{mg}$ in the melatonin group $(\mathrm{P}<0.001)$, with a significant decrease $(\mathrm{P}<0.001)$ in the mean infusion rate of bupivacaine required for controlling the pain, from $0.17 \pm 0.014 \mathrm{~mL} / \mathrm{kg} / \mathrm{hour}$ in the TE group to $0.12 \pm 0.001 \mathrm{~mL} / \mathrm{kg} /$ hour in the melatonin group. The duration of bupivacaine infusion in the melatonin group was also significantly shorter than in the TE group $(96.48 \pm$ 1.87 and $100.05 \pm 3.39$ hours, resp., $\mathrm{P}<0.001)$.

Conclusion: We conclude that premedication of patients with $5 \mathrm{mg}$ melatonin is associated with significant prolongation of thoracic epidural analgesic effects compared to placebo.

Registration: This clinical study was registered at Pan African Clinical Trial Registry with no. "PACTR 201711002741378" on 02-11-2017.

Keywords: melatonin, thoracic epidural analgesia, fracture ribs, acute pain, visual analogue score

\section{Introduction}

Multiple fractured ribs (MFRs) can be associated with severe pain. Moreover, lack of adequate analgesia, especially in the presence of pulmonary contusion and flail chest, can result in serious pulmonary complications. ${ }^{1}$

Thoracic epidural analgesia (TEA) remains a key component of anesthesiabased acute pain services and is used to treat acute pain after thoracic surgery, abdominal surgery, and rib fractures. TEA is commonly used for pain relief in MFR cases, but epidural analgesia has been associated with possible complications, such as epidural hematoma and abscess collection in the spinal space. ${ }^{2-4}$

Melatonin has sedative, hypnotic, analgesic, anti-inflammatory, and antioxidative properties that make it an attractive option as a premedication drug. ${ }^{3}$ It has
Correspondence: Alaa Ali M Elzohry Department of Anesthesia, ICU and Pain Relief, South Egypt Cancer Institute, Assiut University, Assiut, Egypt Tel +201007356462

Email alaa.zohiry@hotmail.com 
been utilized during surgical operating conditions and has been shown to enhance and improve both preoperative and postoperative analgesia. ${ }^{5,6}$

The aim of this study is to evaluate the effects of oral melatonin with thoracic epidural for managing pain in patients with multiple bilateral fractured ribs. Our primary outcome was the total required rescue analgesia, while the secondary outcome was the severity of pain sensation.

\section{Patients and Methods}

A prospective, double-blind randomized control study was carried out on 80 patients, American Society of Anesthesiologists (ASA) Grade I and II, aged above 18 years of either sex, presenting with multiple bilateral fractured ribs between November 2017 and October 2018 in the trauma unit of Tanta and Assiut university hospitals. The study was carried out after approval from the Ethics Committee of both hospitals, approval code 31821/10/17, and was registered at Pan African Clinical Trial Registry, no.PACTR201711002741378, on 02-11-2017. This trial was conducted in accordance with the Declaration of Helsinki.

The patients were adequately informed of the study's purpose, technique, benefits, risks, and methods to overcome these risks. A signed informed written consent was obtained from all the patients who accepted to participate in the study.

Patients excluded from the study included those with known sensitivity to melatonin or pregabalin or any other medicine, a history of drug dependency or substance addiction, or a history of drug or alcohol abuse; those taking opioids or sedative medications or with a history of taking pregabalin or gabapentin; those suffering from pathological rib fractures or kyphoscoliosis or from psychotic disorder or cognitive impairment; those with a body mass index $(\mathrm{BMI})<18.5$ or $>30 \mathrm{~kg} / \mathrm{m}^{2}$ or a history of cerebrovascular disease, seizure disorders, or central nervous system diseases; and those with coagulation disorders and local skin infection at the side of injection.

Routine investigations, such as complete blood count, kidney functions, arterial blood gases (ABG), and prothrombin time/partial thromboplastin time, were conducted immediately upon patients' arrival to the trauma resuscitation room. Noninvasive monitors, such as the electrocardiograph, noninvasive blood pressure (NIBP) monitor, and pulse oximetry, were attached to each patient, and baseline parameters, such as heart rate, mean arterial pressure, and peripheral oxygen saturation $\left(\mathrm{Spo}_{2}\right)$, were recorded.
Simple randomization using a randomization table from a statistics book was done. The study participants were randomly allocated to two groups: 40 patients each at 1:1 allocation ratio, using sealed opaque envelopes.

Placebo group included patients who received oral placebo tablets plus thoracic epidural analgesia. Melatonin group included patients who received oral melatonin tablets $5 \mathrm{mg}$ (brand name; N-acetyl-5-methoxytryptamine, pineal hormone melatonin, and generic name: melatonin) plus thoracic epidural analgesia.

Patients of both groups received $5 \mathrm{mg}$ tablets (either melatonin or placebo) about 1 hour before thoracic epidural insertion and then every 12 hours till the cessation of bupivacaine infusion.

In both groups, the thoracic epidural catheter was inserted close to the middle level of the fractured ribs, patients in sitting position, using an 18-gauge epidural needle for locating the thoracic epidural space by loss of resistance to air technique. Once the loss of resistance was identified, the depth of the needle was recorded. Then, a 20 -gauge multiple side holes epidural catheter (B. Braun ${ }^{\circledR}$ ) was inserted $5 \mathrm{~cm}$ after the loss of resistance depth. Then, after securing the catheter in place, a test dose (three $\mathrm{mL}$ of lidocaine $2 \%$ mixed with epinephrine 1:200,000) was given, and the patients were monitored for 3 minutes. Bupivacaine $0.25 \%$ (one $\mathrm{mL} /$ segment) was then administered as a bolus, followed by continuous infusion of bupivacaine $0.125 \%$ at a rate of $0.1 \mathrm{~mL} / \mathrm{kg} /$ hour, if the test dose was proven negative. All epidural catheters in both groups were inserted by the same expert consultant of anesthesia.

At the high-dependency unit, bupivacaine infusion was continued until complete and consistent pain relief was achieved ( 2 recordings of VAS $\leq 3$ ). By this time, all the patients had received diclofenac $(1 \mathrm{mg} / \mathrm{kg})$ and paracetamol ( $1 \mathrm{gm}) \mathrm{IV}$ infusion every 8 hours and gradually tapered off the local anesthetic infusion over a period of 12 hours to 24 hours.

Visual analog scale (VAS) pain score was recorded in both groups at baseline before the administration of any analgesic, 30 minutes after the epidural bolus of local anesthetic, and then every 2 hours for the first 24 hours, every 6 hours on the second day, every 12 hours on the third day, and every 24 hours on the fourth and fifth days. If the pain score exceeds 4 despite bupivacaine infusion, rescue analgesia in the form of titrated bolus doses of $0.01 \mathrm{mg} \backslash \mathrm{kg}$ morphine was administered slowly IV. $\mathrm{SpO}_{2}$ and arterial blood base analysis was done and $\mathrm{PaO}_{2}$ and $\mathrm{PaCO}_{2}$ were recorded at baseline before administration of any analgesic, after 1 hour, and every 6 hours for the first 24 hours . 
The mean infusion rate of the analgesic bupivacaine controlling the pain, duration of infusion, total rescue analgesia consumption, and complications such as drowsiness (no eye opening in response to verbal commands), dizziness, hypotension, bradycardia, dry mouth, and nausea/vomiting were recorded.

The quality of sleep at night was reported by the patients for 3 days, as very good, good, fair, bad, or very bad, using the Consensus Sleep Diary. ${ }^{6,7}$ The concept of the sleep diary was explained to the patients in the preoperative period. They were asked to fill in the self-assessment questionnaire preoperatively, on the night following the surgery, and 1 week after the surgery, to be able to rate their sleep quality.

All measurement data were collected by a chief nurse not involved in the study and blind to the medication used in both groups.

\section{Statistical Analysis}

The Statistical Package for the Social Sciences (SPSS 22, IBM, Armonk, NY, USA) was used in the statistical analysis of the measured data by unpaired $t$-test for parametric data (expressed as a mean and standard deviation) and Fisher's exact test for categorical data (expressed as a number and percent). The pain score, the response to gag reflex, the degree of swallowing, and the guardians' satisfaction were assessed by the Mann-Whitney test. When the P-value was less than 0.05 , the changes were considered significant.

\section{Results}

A pilot study was conducted to assess the effects of preadministration of melatonin before thoracic epidural analgesia on the time for the first request for pethidine rescue analgesia on 10 patients (not included in the final study) presenting with multiple bilateral fractured ribs and the results were encouraging in the favor of Melatonin group.

In the final study, we found that; preadministration of melatonin significantly decreased the required total consumption of morphine as rescue analgesia from $31.8 \pm$ $1.41 \mathrm{mg}$ to $13.03 \pm 0.85 \mathrm{mg}$. Based upon these results, at least 40 patients in each group were required to detect a significant decrease in the required total consumption of morphine as rescue analgesia, $18.77 \mathrm{mg}$ at an $\alpha$ value of 0.05 and $90 \%$ power of the study.

A total of 89 patients were considered eligible for this clinical study. However, 9 patients were excluded due to not meeting the inclusion criteria (from the 9 patients, 5 had a history of substance addiction, 3 had a history of taking pregabalin or gabapentin, and 1 suffered from pathological rib fractures). The remaining 80 patients were randomly divided into two equal groups. Data from all patients were successfully collected (Figure 1).

The mean age of our patients was $25.23 \pm 1.17$ in the Placebo group and $25.15 \pm 1.15$ in the melatonin group. The majority of them were males, with no significant difference between both groups in demographic data and the number of fractured ribs (Table 1).

In both groups, there was an improvement in arterial oxygen saturation $\left(\mathrm{SpO}_{2}\right)$ and arterial oxygen tension $\left(\mathrm{PaO}_{2}\right)$, without a significant difference between both groups during the first 24 hours after the start of bupivacaine infusion in the thoracic epidural catheter (Table 2). Simultaneously, there was a decrease in arterial carbon dioxide concentration $\left(\mathrm{PCO}_{2}\right)$ in both groups, without a significant difference between them (Table 2).

The visual analog score improved significantly in both groups with continuous infusion of bupivacaine, without a significant difference between them (Figures 2 and 3).

Melatonin administration was associated with a significant decrease $(\mathrm{P}<0.001)$ in the mean infusion rate of bupivacaine required for controlling the pain, from $0.17 \pm 0.014 \mathrm{~mL} / \mathrm{kg} /$ hour in placebo group patients to 0.12 $\pm 0.001 \mathrm{~mL} / \mathrm{kg} /$ hour in melatonin group patients. Also, the duration of bupivacaine infusion in placebo group was significantly shorter than that in melatonin group (96.48 \pm 1.87 and $100.05 \pm 3.39$ hours, resp., $\mathrm{P}<0.001$ ), and the required total morphine analgesia consumption significantly decreased from $31.8 \pm 1.41 \mathrm{mg}$ in group I to $13.03 \pm 0.85 \mathrm{mg}$ in group II $(\mathrm{P}<0.001)$ (Table 3$)$.

In the melatonin group, the majority of the cases (52.5\%) complained from nausea and vomiting, versus only $15 \%$ in the placebo group, with a significant difference between both groups $(\mathrm{P}<0.001)$. On the other hand, the presence of other complications, such as bradycardia, dry mouth, drowsiness, and dizziness, was comparable between both groups ( $\mathrm{P}=1.54,1$ and 1, resp.) (Table 4)

$>$ In the placebo group, the majority of cases experienced either poor or fair quality of sleep $(12.5 \%)$ on the first night. The percentage increased on the second and third nights to $57.5 \%$ and $77.5 \%$, respectively. However, in the melatonin group, the majority of the cases $(50 \%)$ experienced fair sleep on the first night. On the second night, the quality of sleep improved to good in $50 \%$, and on the third, $70 \%$ of the patients experienced very good sleep (Table 5). 


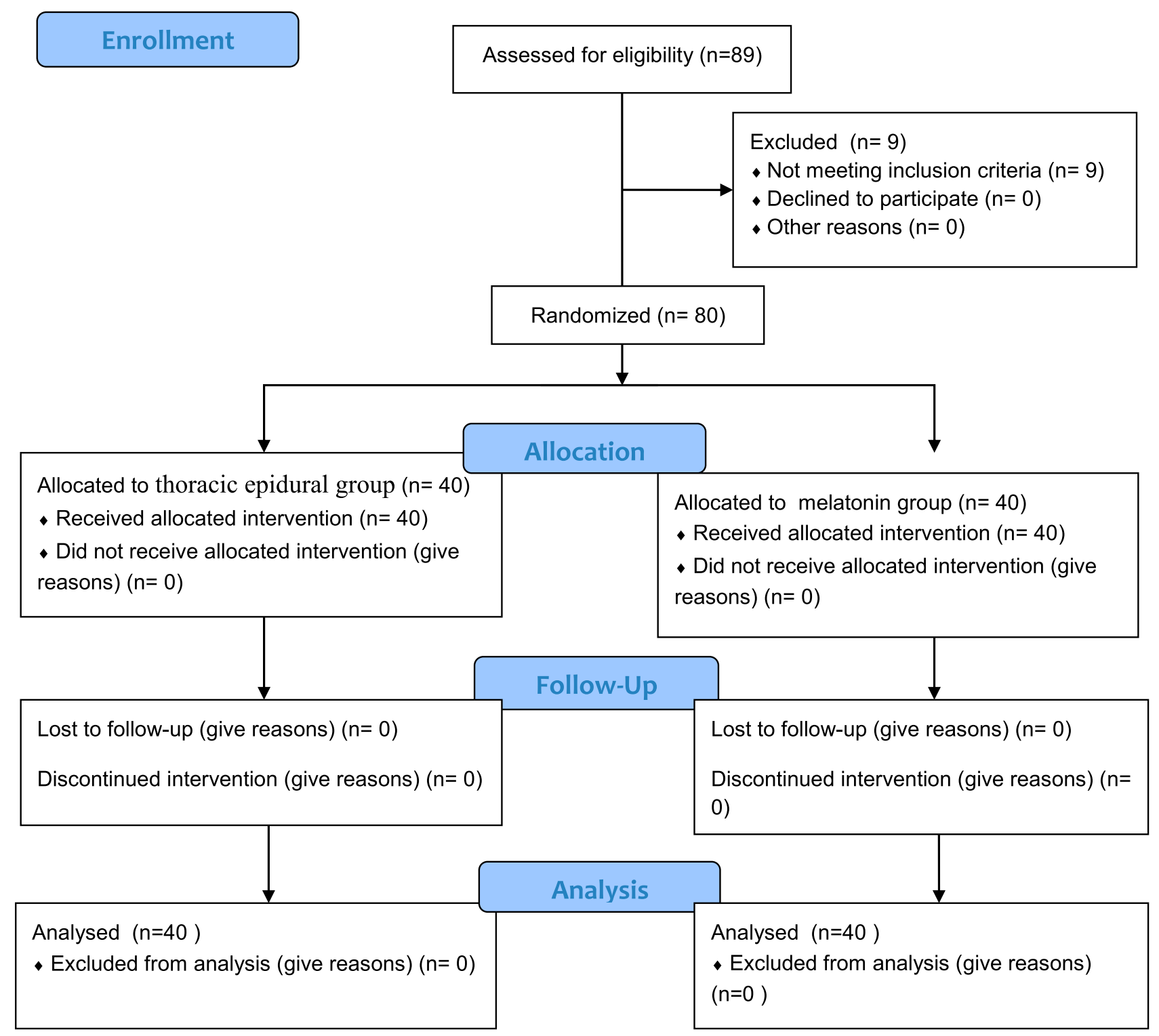

Figure I Flow chart.

\section{Discussion}

Multiple pain relief treatment options are available. However, recent studies show that NSAIDs increase the risk of cardiac morbidity and stroke, in addition to wellknown adverse effects, such as renal failure and GI-tract bleeding. Moreover, opioids increase the risk of adverse effects, such as sedation, dizziness, postoperative nausea and vomiting (PONV), urine retention, itching, and respiratory complications. ${ }^{8,9}$

Multimodal analgesia is the recommended analgesic strategy, and so melatonin is a promising drug. ${ }^{8}$ The possible mechanism and site of antinociception action of melatonin, however, are not clear. Possible mechanisms of action include controlling the pro-inflammatory mediator release, inhibiting the activation of nociceptor receptor and subsequent pain perception in the brain, and promoting sleep and improving its quality, which plays a major role in modifying pain perception. Its action mediated via glutamate, $\gamma$-aminobutyric acid, opioid neurotransmission, or melatonin receptor may also explain its effect. Other alternative mechanisms include scavenging free radicals or inhibiting nitric oxide synthase. ${ }^{10}$ Many experimental studies have evaluated the antinociceptive, antihyperalgesic, anti-inflammatory, and anti-allodynic actions of exogenous melatonin. ${ }^{5,10}$ Exogenous melatonin was administered intraperitoneally, intrathecally, intravenously, subcutaneously, and orally, in doses ranging from 0.1 to $300 \mathrm{mg} / \mathrm{kg}$. Several pain models were employed, 
Table I Demographic Data in Both Groups

\begin{tabular}{|c|c|c|c|c|}
\hline \multicolumn{2}{|c|}{ Variables } & $\begin{array}{l}\text { Placebo } \\
\text { Group }\end{array}$ & $\begin{array}{l}\text { Melatonin } \\
\text { Group }\end{array}$ & $P$ value \\
\hline \multirow{2}{*}{\multicolumn{2}{|c|}{$\begin{array}{l}\text { Age }(y) \\
\text { BMI }\left(\mathrm{kg} / \mathrm{m}^{2}\right)\end{array}$}} & $25.23 \pm 1.17$ & $25.15 \pm 1.15$ & 0.776 \\
\hline & & $25.4 \pm 1.11$ & $25.38 \pm 1.13$ & 0.921 \\
\hline \multirow[t]{2}{*}{ Sex } & Male & 32 (80\%) & 33 (82.5\%) & 0.775 \\
\hline & Female & $8(20 \%)$ & 7 (17.5\%) & \\
\hline \multirow[t]{2}{*}{ ASA } & ASA I & 22 (55\%) & 19 (47.5\%) & 0.655 \\
\hline & ASA II & I8 (45\%) & 21 (52.5\%) & \\
\hline \multirow{2}{*}{$\begin{array}{l}\text { Fracture } \\
\text { ribs }\end{array}$} & 3 ribs & $33(82.5 \%)$ & $32(80 \%)$ & 0.775 \\
\hline & 4 ribs & 7 (I7.5\%) & $8(20 \%)$ & \\
\hline
\end{tabular}

mimicking clinical pain states, such as acute pain, inflammatory pain, and chronic neuropathic pain. It is concluded that exogenous melatonin produced significant dosedependent antinociceptive effects in all presented experimental models of pain.

At the level of physiological tests to assess pain, a doubleblind, randomized, placebo-controlled, dose-response experimental study investigated the analgesic effect of exogenous melatonin in humans. ${ }^{11}$ The study included 60 volunteers and quantitative sensory testing (QST) was employed to measure pressure pain threshold/tolerance and pain threshold/tolerance. Sublingual melatonin $(0.05 \mathrm{mg} / \mathrm{kg} ; 0.15 \mathrm{mg} / \mathrm{kg} ; 0.25 \mathrm{mg} / \mathrm{kg})$ or placebo was administered $30 \mathrm{~min}$ before test procedures. QST-variables were significantly increased by exogenous melatonin in a dose-dependent manner. Furthermore, melatonin plasma levels were correlated to analgesic effects.

In our study, the analgesic benefit of melatonin was obvious. Melatonin succeeded in decreasing the infusion rate of bupivacaine, total hours of epidural injection, and total morphine required as rescue analgesia. On the other

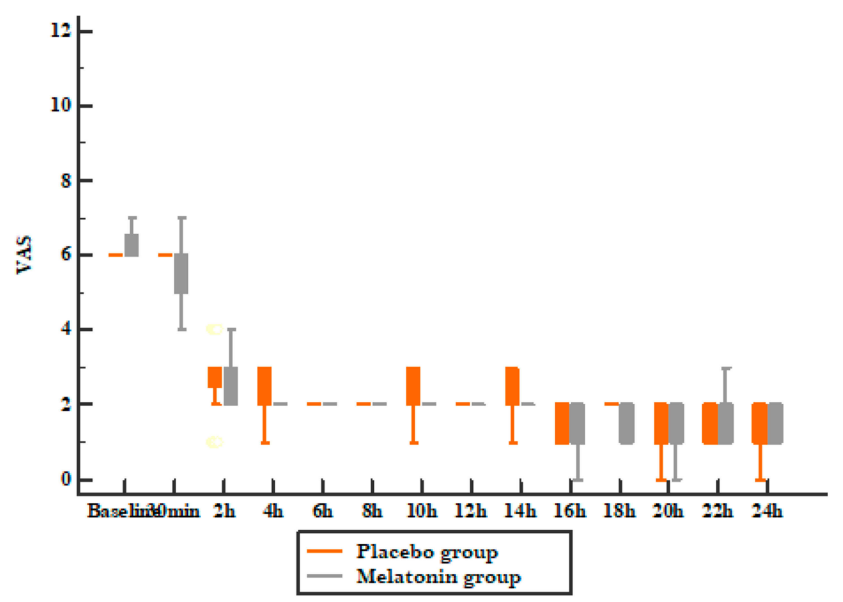

Figure 2 The visual analog score in both groups: in the first 24 hours postoperative.

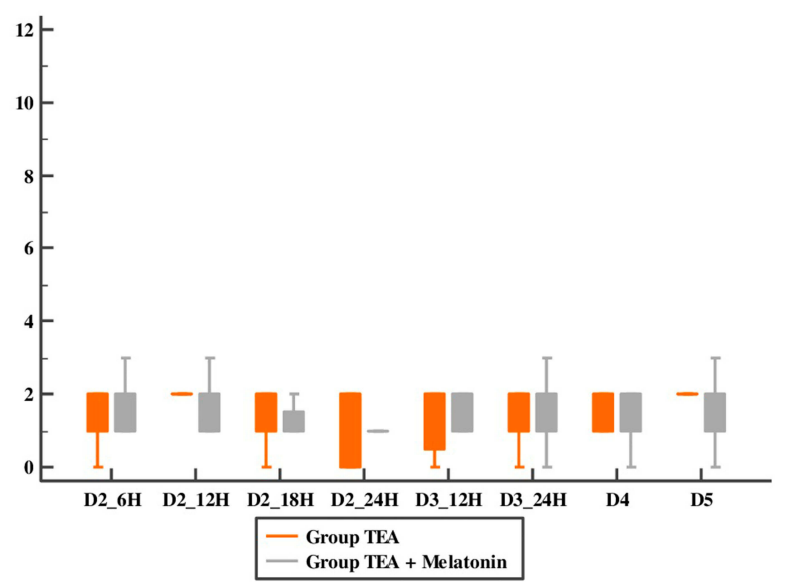

Figure 3 The visual analog score in both groups (2-5 days) postoperative.

hand, the addition of melatonin had no role in the quality of analgesia, as there was no difference in VAS score between the groups in the recorded timelines of the first 3 days.

Table 2 Arterial Oxygen Saturation $\left(\mathrm{SpO}_{2}\right)$, Arterial Oxygen Tension $\left(\mathrm{PaO}_{2}\right)$, Arterial Carbon Dioxide Concentration $\left(\mathrm{PaCO}_{2}\right)$ During First 24 Hours After Start Bupivacaine Infusion in Thoracic Epidural Catheter

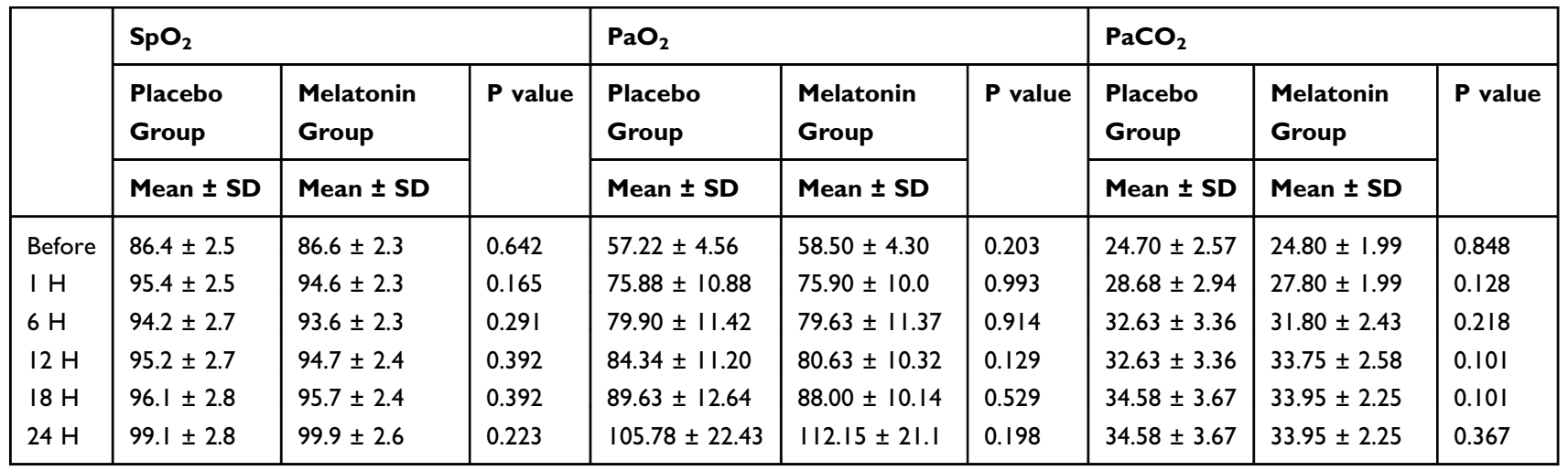


Table 3 Demographic Data, Total Rescue Analgesia Consumption, Mean Infusion Rate of, and Duration of Bupivacaine Infusion

\begin{tabular}{|c|c|c|c|}
\hline Variables & $\begin{array}{l}\text { Placebo } \\
\text { Group }\end{array}$ & $\begin{array}{l}\text { Melatonin } \\
\text { Group }\end{array}$ & $P$ value \\
\hline $\begin{array}{l}\text { Mean infusion rate of analgesic } \\
\text { bupivacaine controlling the pain } \\
\text { (mL/kg/hour) }\end{array}$ & $0.17 \pm 0.014$ & $0.12 \pm 0.001$ & $<0.001$ \\
\hline Duration of infusion (h) & $100.05 \pm 3.39$ & $96.48 \pm 1.87$ & $<0.001$ \\
\hline $\begin{array}{l}\text { Total rescue morphine } \\
\text { consumption }(\mathrm{mg})\end{array}$ & $31.8 \pm 1.41$ & $13.03 \pm 0.85$ & $<0.001$ \\
\hline
\end{tabular}

Table 4 Complication in Both Groups

\begin{tabular}{|l|l|l|l|}
\hline Complications & $\begin{array}{l}\text { Placebo } \\
\text { Group }\end{array}$ & $\begin{array}{l}\text { Melatonin } \\
\text { Group }\end{array}$ & P value \\
\hline Drowsiness and dizziness & 0 & $\mathrm{I}(2.5 \%)$ & $\mathrm{I}$ \\
Hypotension & 0 & 0 & - \\
Bradycardia & $\mathrm{I}(2.5 \%)$ & $\mathrm{I}(2.5 \%)$ & $\mathrm{I} .54$ \\
Dry mouth & 0 & $\mathrm{I}(2.5 \%)$ & $\mathrm{I}$ \\
Nausea/vomiting & $6(15 \%)$ & $2 \mathrm{I}(52.5 \%)$ & $0.000 \mathrm{I}$ \\
\hline
\end{tabular}

Till now, no study has evaluated the role of melatonin in patients with multiple fractured ribs. On the other hand, many studies have evaluated the perioperative use of melatonin during a different surgical procedure. Also, a limited number of randomized studies have indicated that exogenous melatonin can be administered as an analgesic treatment in complex chronic pain states, such as fibromyalgia, ${ }^{12}$ cluster headache, ${ }^{13}$ endometriosis, ${ }^{14}$ and temporomandibular pain disorder. ${ }^{15}$

From the perioperative surgical aspect, a randomized placebo-controlled study was done on 52 patients administered with $6 \mathrm{mg} \times 2$ oral melatonin before open prostatectomy. The study documented reduced intra- and postoperative analgesic consumption and reduced postoperative pain intensity ratings. ${ }^{16}$

Similarly, two randomized studies, including 33 and 59 patients administered with $5 \mathrm{mg}$ x 2 oral melatonin before open hysterectomy, reported that melatonin reduced postoperative analgesic consumption and postoperative pain intensity ratings compared to placebo. ${ }^{17,18}$
In ophthalmological procedures, a randomized study including 40 patients, administered with $10 \mathrm{mg}$ oral melatonin, documented reduced intraoperative analgesic consumption and reduced intra- and postoperative pain intensity ratings compared to placebo. ${ }^{19}$

Another randomized placebo-controlled study including 40 patients undergoing hand surgery, receiving $10 \mathrm{mg}$ oral melatonin, documented reduced intra- and postoperative analgesic consumption and reduced intraoperative pain intensity ratings. ${ }^{20}$

Finally, a randomized placebo-controlled study including 53 patients undergoing laparoscopic cholecystectomy, administered with $3 \mathrm{mg}$ x 2 sublingual melatonin before surgery, documented reduced intraoperative analgesic consumption. $^{21}$

However, other randomized studies for different surgical procedures did not document any clinical effects of exogenous melatonin with respect to either analgesic consumption or pain intensity ratings compared to placebo. ${ }^{22,23}$

Khezri et $\mathrm{al}^{22}$ and Naguib and Samarkandi ${ }^{23}$ have observed that melatonin is a valuable anxiolytic without observable analgesic properties. The study by Khezri ${ }^{22}$ was conducted on cataract surgery under topical and intracameral anesthesia. Verbal pain score was assessed during surgery and in the recovery room. On the other hand, the study by Naguib and Samarkandi ${ }^{23}$ was conducted on the laparoscopic gynecological procedures and was limited to intraoperative fentanyl consumption and morphine consumption in the recovery room.

In this study, although improvement in the $\mathrm{PaO}_{2}$ over the first 24 hours was convergent without a statistical difference, it was attributed to the effective analgesia promoting adequate breathing with effective coughing. Consequently, improvement in carbon dioxide tension and $\mathrm{PH}$ was convergent without statistical difference.

Surgery and tissue injury alter normal circadian pattern of melatonin production. Using the Consensus Sleep Diary

Table 5 The Quality of Sleep of the Patients Assessed by Consensus Sleep Diary in Both Groups

\begin{tabular}{|l|l|l|l|l|l|l|l|l|l|l|l|}
\hline Quality of the sleep & \multicolumn{4}{l|}{ Placebo Group } & \multicolumn{3}{l|}{ Melatonin Group } \\
\cline { 3 - 11 } & $\begin{array}{l}\text { Very } \\
\text { poor }\end{array}$ & Poor & Fair & Good & $\begin{array}{l}\text { Very } \\
\text { good }\end{array}$ & $\begin{array}{l}\text { Very } \\
\text { poor }\end{array}$ & Poor & Fair & Good & $\begin{array}{l}\text { Very } \\
\text { good }\end{array}$ \\
\hline Number and Percentage of & Ist night & $5(12.5)$ & $15(12.5)$ & $15(12.5)$ & $5(12.5)$ & 0 & 0 & 0 & $20(50)$ & $19(47.5)$ & $1(2.5)$ \\
patients & 2nd night & $2(5)$ & $5(12.5)$ & $23(57.5)$ & $9(22.5)$ & $1(2.5)$ & 0 & 0 & $13(32.5)$ & $7(17.5)$ & $20(50)$ \\
& 3rd night & 0 & 0 & $31(77.5)$ & $5(12.5)$ & $4(10)$ & 0 & 0 & $7(17.5)$ & $5(12.5)$ & $28(70 \%)$ \\
\hline
\end{tabular}

Note: Data were presented as percentage (\%) and number. 
on the first three nights showed that the sleep quality was obviously better in patients who received melatonin.

A recent meta-analysis ${ }^{7}$ investigated sleep latency, overall sleep quality, and total sleep time in patients suffering from primary sleep disorders. The analysis included 19 randomized placebo-controlled studies $(n=1683)$. Patients received melatonin from 7 days up to 182 days in doses ranging between $0.1-5 \mathrm{mg}$ and $0.05-0.15 \mathrm{mg} / \mathrm{kg}$. Melatonin reduced the latency of sleep onset, improved overall sleep quality, and increased the total sleep time.

Drowsiness and dizziness, the postulated side effects to occur with the usage of melatonin, occurred only in one patient from the melatonin group. However, it is not an annoying side effect. Also, melatonin does not aggravate hypotension and bradycardia, which may occur with TE.

A group of 120 patients scheduled for cesarean section under spinal anesthesia were randomly divided into 3 groups-group M3 receiving sublingual melatonin $3 \mathrm{mg}$, group M6 receiving melatonin $6 \mathrm{mg}$, and group P (placebo) - 20 minutes before spinal anesthesia. There were no significant differences between the three groups in terms of side effects, either intraoperatively or postoperatively, including pruritus, nausea/vomiting, vertigo, dizziness, and respiratory depression. ${ }^{24}$

Some researchers have reported that premedication by oral melatonin 3 or $5 \mathrm{mg}$ can reduce the need for propofol for induction and not increase the post-anesthesia recovery stay period. $^{25}$

Limitations to our study include the small sample size involved. As there are many dose regimens of primitive use of melatonin as part of multimodal analgesia, we recommend more studies to compare between different doses in fractured ribs and to compare between the exclusive use of melatonin and different methods to reach a satisfactory patient outcome.

\section{Conclusion}

Based on the available evidence, melatonin had beneficial effect in analgesia. It is a safe, available, and inexpensive perioperative option for clinical practice. The premedication of patients with $5 \mathrm{mg}$ melatonin has been associated with prolonged analgesic effects of thoracic epidural compared to placebo.

However, more studies are required to identify long-term effects, such as incidence of chronic pain, and to evaluate its value among patients undergoing thoracic surgery.

\section{Data Sharing Statement}

The authors don't intend to share individual deidentified participant data. No specific data or study-related document will be shared. Only the mentioned data in the manuscript will be available.

\section{Funding}

The authors have no sources of funding to declare for this manuscript. This research did not receive any specific grant from funding agencies in the public, commercial, or not-for-profit sectors.

\section{Disclosure}

The authors declare no conflicts of interest.

\section{References}

1. Sirmali M, Türüt H, Topçu S, et al. A comprehensive analysis of traumatic rib fractures: morbidity, mortality and management. Eur J Cardiothorac Surg. 2003;24(1):133-138. doi:10.1016/S1010-7940(03)00256-2

2. Auroy Y, Narchi P, Messiah A, Litt L, Rouvier B, Samii K. Serious complications related to regional anesthesia: results of a prospective survey in France. Anesthesiology. 1997;87(3):479-486.

3. Yousaf F, Seet E, Venkatraghavan L, Abrishami A, Chung F. Efficacy and safety of melatonin as an anxiolytic and analgesic in the perioperative period: a qualitative systematic review of randomized trials. Anesthesiology. 2010;113(4):968-976. doi:10.1097/ALN.0b013e318 $1 \mathrm{e} 7 \mathrm{~d} 626$

4. Srinivasan V, C. Lauterbach E, Yu Ho K, Acuna-Castroviejo D, Zakaria R, Brzezinski A. Melatonin in antinociception: its therapeutic applications. Curr Neuropharmacol. 2012;10(2):167-178. doi:10.217 4/157015912800604489

5. Ambriz-Tututi M, Rocha-González HI, Cruz SL, Granados-Soto V. Melatonin: a hormone that modulates pain. Life Sci. 2009;84(15-16): 489-498. doi:10.1016/j.lfs.2009.01.024

6. Carney CE, Buysse DJ, Ancoli-Israel S, et al. The consensus sleep diary: standardizing prospective sleep self-monitoring. Sleep. 2012;35(2):287-302. doi:10.5665/sleep.1642

7. Ferracioli-Oda E, Qawasmi A, Bloch MH. Meta-analysis: melatonin for the treatment of primary sleep disorders. Focus. 2014;12 (1):73-79. doi:10.1176/appi.focus.12.1.73

8. Andersen L. The analgesic effects of exogenous melatonin in humans. Dan Med J. 2016;63(10).

9. Kehlet H. Postoperative opioid sparing to hasten recovery: what are the issues? Anesthesiology. 2005;102(6):1083-1085. doi:10.1097/ 00000542-200506000-00004

10. Srinivasan V, Pandi-Perumal SR, Spence DW, et al. Potential use of melatonergic drugs in analgesia: mechanisms of action. Brain Res Bull. 2010;81(4-5):362-371.

11. Stefani LC, Muller S, Torres ILS, et al. A Phase II, randomized, double-blind, placebo controlled, dose-response trial of the melatonin effect on the pain threshold of healthy subjects. PLoS One. 2013;8 (10):e74107. doi:10.1371/journal.pone.0074107

12. de Zanette SA, Vercelino R, Laste G, et al. Melatonin analgesia is associated with improvement of the descending endogenous pain-modulating system in fibromyalgia: a phase II, randomized, double-dummy, controlled trial. BMC Pharmacol Toxicol. 2014;15 (1):40. doi:10.1186/2050-6511-15-40 
13. Leone M, D’Amico D, Moschiano F, Fraschini F, Bussone G. Melatonin versus placebo in the prophylaxis of cluster headache: a double-blind pilot study with parallel groups. Cephalalgia. 1996;16 (7):494-496. doi:10.1046/j.1468-2982.1996.1607494.x

14. Schwertner A, Conceição Dos Santos CC, Costa GD, et al. Efficacy of melatonin in the treatment of endometriosis: A phase II, randomized, double-blind, placebo-controlled trial. $P A I N^{\circledR}$. 2013;154 (6):874-881. doi:10.1016/j.pain.2013.02.025

15. Vidor LP, Torres ILS, Custódio de Souza IC, Fregni F, Caumo W. Analgesic and sedative effects of melatonin in temporomandibular disorders: a double-blind, randomized, parallel-group, placebo-controlled study. J Pain Symptom Manage. 2013;46(3):422-432. doi:10.1016/j. jpainsymman.2012.08.019

16. Borazan H, Tuncer S, Yalcin N, Erol A, Otelcioglu S. Effects of preoperative oral melatonin medication on postoperative analgesia, sleep quality, and sedation in patients undergoing elective prostatectomy: a randomized clinical trial. J Anesth. 2010;24(2):155-160. doi:10.1007/s00540-010-0891-8

17. Caumo W, Torres F, Moreira NL, et al. The clinical impact of preoperative melatonin on postoperative outcomes in patients undergoing abdominal hysterectomy. Anesth Analg. 2007;105 (5):1263-1271. doi:10.1213/01.ane.0000282834.78456.90

18. Caumo W, Levandovski R, Hidalgo MPL. Preoperative anxiolytic effect of melatonin and clonidine on postoperative pain and morphine consumption in patients undergoing abdominal hysterectomy: a double-blind, randomized, placebo-controlled study. $J$ Pain. 2009;10(1):100-108. doi:10.1016/j.jpain.2008.08.007
19. Ismail SA, Mowafi HA. Melatonin provides anxiolysis, enhances analgesia, decreases intraocular pressure, and promotes better operating conditions during cataract surgery under topical anesthesia. Anesth Analg. 2009;108(4):1146-1151. doi:10.1213/ane.0b013e3181907ebe

20. Mowafi HA, Ismail SA. Melatonin improves tourniquet tolerance and enhances postoperative analgesia in patients receiving intravenous regional anesthesia. Anesth Analg. 2008;107(4):1422-1426. doi:10.1213/ane.0b013e318181f689

21. Ionescu D, Bãdescu C, Ilie A, et al. Melatonin as premedication for laparoscopic cholecystectomy: a double-blind, placebo-controlled study. South Afr J Anaesth Analg. 2008;14(4):8-11. doi:10.1080/ 22201173.2008.10872555

22. Kirksey MA, Yoo D, Danninger T, Stundner O, Ma Y, Memtsoudis SG. Impact of melatonin on sleep and pain after total knee arthroplasty under regional anesthesia with sedation: a double-blind, randomized, placebo-controlled pilot study. $J$ Arthroplasty. 2015;30 (12):2370-2375. doi:10.1016/j.arth.2015.06.034

23. Naguib M, Samarkandi AH. Premedication with melatonin: a double-blind, placebo-controlled comparison with midazolam. $\mathrm{Br}$ J Anaesth. 1999;82(6):875-880. doi:10.1093/bja/82.6.875

24. Beigom Khezri M, Delkhosh Reihany M, Oveisy S, Mohammadi N. Evaluation of the analgesic efficacy of melatonin in patients undergoing cesarean section under s pinal anesthesia: a prospective randomized double-blind study. Iran J Pharm Res. 2016;15(4):963-971.

25. Turkistani A, Abdullah KM, Al-Shaer AA, Mazen KF, Alkatheri K. Melatonin premedication and the induction dose of propofol. Eur J Anaesthesiol. 2007;24(5):399-402. doi:10.1017/S0265021506001505
Local and Regional Anesthesia

\section{Publish your work in this journal}

Local and Regional Anesthesia is an international, peer-reviewed, open access journal publishing on the development, pharmacology, delivery and targeting and clinical use of local and regional anesthetics and analgesics. The journal welcomes submitted papers covering original research, basic science, clinical studies, reviews \&

\section{Dovepress}

evaluations, guidelines, expert opinion and commentary, case reports and extended reports. The manuscript management system is completely online and includes a very quick and fair peer-review system, which is all easy to use. Visit http://www.dovepress.com/testimonials. php to read real quotes from published authors. 